\title{
Comparison of an Isolated bidirectional Dc-Dc converter with and without a Flyback Snubber
}

\author{
Rejitha. $S^{1}$, Sreedevi.G ${ }^{2}$ \\ ${ }^{1,2}$ (Electrical and Electronics Engineering, Govt.Engineering College Idukki/M.G.University, India)
}

\begin{abstract}
Renewable energy sources like solar and fuel cells are emerging as a promising supplementary power sources due to their merits of cleanness, high efficiency, and high reliability. But the output levels of these are low. An isolated bidirectional full-bridge dc-dc converter can be used for interfacing battery to the system. Because of the presence of leakage inductance of the isolation transformer voltage spikes are produced. An isolated bidirectional converter with a flyback snubber can reduce voltage spike caused by the current difference between the current-fed inductor and leakage inductance of the isolation transformer. In this work an isolated bidirectional full bridge dc-dc converter with and without flyback snubber is simulated using MATLAB SIMULINK Tool and compared the simulation results. Also implemented the hardware of boost mode operation of the same converter with input as $10 \mathrm{~V}$ and compared it with the simulation results.
\end{abstract}

Keywords: Clamping capacitor, Flyback snubber, , Isolated bidirectional Dc-Dc converter, Leakage inductance, Voltage spikes

\section{INTRODUCTION}

A DC-to-DC converter is an electronic circuit which converts a source of direct current (DC) from one voltage level to another. Applications of renewable energy sources have been getting more awareness. Because of the increasing demand of the renewable energy sources like fuel cell, solar energy etc, batteries are necessary for storing and supplying energy. For charging and discharging of the batteries a converter which can operate in both directions is required. Bidirectional converters are the main part of a system where it is necessary to interface an energy storage device to a renewable energy sources like fuel cell, solar cell etc. Therefore bidirectional converters are getting more importance for past decades. Bidirectional converters can be isolated and nonisolated. Both of them have its own advantages and disadvantages. In applications where high power is required, bridge-type bidirectional converters are become an important [5-7] . A dual full-bridge configuration is usually used for raising the power level and its low side and high side are configured with boost type and buck-type topologies, respectively. Isolation is used for isolating the low voltage and high voltage side. There is many problems associated with these topologies.

Most important problem is due to the leakage inductance of the isolation transformer, which will result in high voltage spike during switching transition. And the current freewheeling due to the leakage inductance will increase conduction loss. A passive or an active clamp circuit can be used to solve this problem. Passive and active clamping circuits can be used to suppress the voltage spikes due to the current difference between the current-fed inductor and leakage inductance of the isolation transformer. To clamp the voltage, $R C D$ passive snubber can be used, which is a simple method. The energy absorbed in the clamping capacitor is dissipated on the resistor. But the disadvantage is the reduction efficiency due to the power loss in the resistor. A flyback snubber can be used to recycle the absorbed energy in the clamping capacitor [1]. The current does not circulate through the full-bridge switches, their current stresses can be reduced. Then it improves system reliability significantly. Additionally, during start-up, the flyback snubber can be controlled to precharge the high-side capacitor, improving feasibility significantly.

The main objective of this work is to simulate an isolated bidirectional converter with and without flyback snubber and compare the simulation results. Also implement the hardware of the converter in boost mode with flyback snubber and compare it with the simulation results.

\section{OPERATION OF THE CONVERTER}

An isolated bidirectional de- de converter without flyback snubber is shown in fig 1 and without flyback snubber is shown in fig 2 . The isolated bidirectional converter can be operated in two modes . buck mode and boost mode. Figure 2 consists of a current-fed switch bridge, a flyback snubber at the low-voltage side, and a voltage-fed bridge at the high-voltage side. 


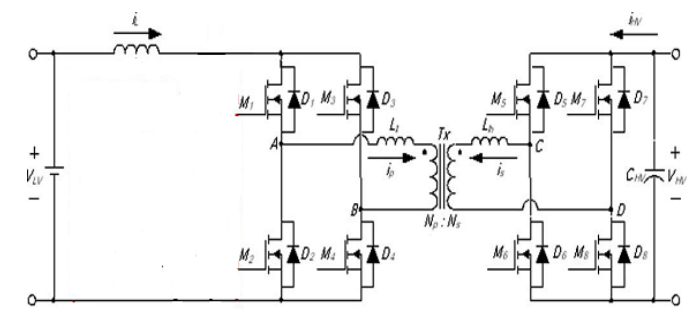

Figure 1.Isolated Bidirectional Dc-Dc Converter Without A Flyback Snubber

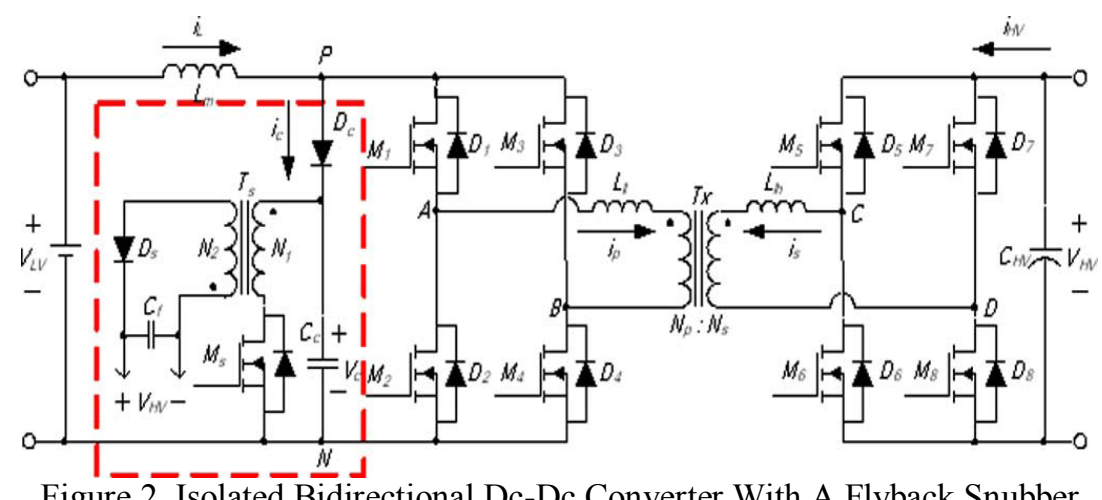

Figure 2. Isolated Bidirectional Dc-Dc Converter With A Flyback Snubber

Inductor Lm at the low voltage side performs output filtering when power flows from the high-voltage side to the batteries, which is denoted as a buck mode. On the other hand, it works in boost mode when power is transferred from the batteries to the high-voltage side. Also clamp branch capacitor $\mathrm{C}_{\mathrm{C}}$ and diode $\mathrm{D}_{\mathrm{C}}$ are used to absorb the current difference between current-fed inductor $\mathrm{Lm}$ and leakage inductance $\mathrm{L}_{11}$ and $\mathrm{L}_{\mathrm{lh}}$ of isolation transformer Tx during switching commutation. The flyback snubber can be independently controlled to regulate $\mathrm{V}_{\mathrm{C}}$ to the desired value. Thus, the voltage stress of switches $\mathrm{M}_{1}-\mathrm{M}_{4}$ can be limited to a low level. The major merits of this bidirectional converter configuration include no spike current circulating through the power switches and clamping the voltage across switches $\mathrm{M}_{1}-\mathrm{M}_{4}$, improving system reliability significantly. Note that high spike current can result in charge migration, over current density, and extra magnetic force, which will deteriorate in MOSFET carrier density, channel width, and wire bonding and, in turn, increase its conduction resistance.

A bidirectional dc-dc converter has two types of conversions: step-up conversion (boost mode) and step-down conversion (buck mode). In boost mode, switches $\mathrm{M}_{1}-\mathrm{M}_{4}$ are controlled, and the body diodes of switches $\mathrm{M}_{5}-\mathrm{M}_{8}$ are used as a rectifier. In buck mode, switches $\mathrm{M}_{5}-\mathrm{M}_{8}$ are controlled, and the body diodes of switches $\mathrm{M}_{1}-\mathrm{M}_{4}$ operate as a rectifier. To simplify the steady-state analysis, several assumptions are made, which are as follows. inductance.

1) All components are ideal. The transformer is treated as an ideal transformer associated with leakage

2) Inductor $\mathrm{Lm}$ is large enough to keep current $\mathrm{i}_{\mathrm{L}}$ constant over a switching period.

3) Clamping capacitor $C_{C}$ is much larger than parasitic capacitance of switches $M_{1}-M_{8}$.

\section{Step-Up Conversion}

In boost mode, switches $\mathrm{M}_{1}-\mathrm{M}_{4}$ are operated like a boost converter, where switch pairs $\left(\mathrm{M}_{1}, \mathrm{M}_{2}\right)$ and $\left(\mathrm{M}_{3}, \mathrm{M}_{4}\right)$ are turned $\mathrm{ON}$ to store energy in Lm. At the high-voltage side, the body diodes of switches $\mathrm{M}_{5}-\mathrm{M}_{8}$ will conduct to transfer power to $V_{H V}$. When switch pair $\left(M_{1}, M_{2}\right)$ or $\left(M_{3}, M_{4}\right)$ is switched to $\left(M_{1}, M_{4}\right)$ or $\left(M_{2}\right.$ ,$\left.M_{3}\right)$, the current difference $i_{C}\left(=i_{L}-i_{p}\right)$ will charge capacitor $C_{C}$, and then, raise $i_{p}$ up to $i_{L}$. The clamp branch is mainly used to limit the transient voltage imposed on the current-fed side switches. Moreover, the flyback converter can be controlled to charge the high-voltage-side capacitor to avoid over current. The clamp branch and the flyback snubber are activated during both start-up and regular boost operation modes.

In this converter $V_{C}(R)$ represents the regulated $V_{C}$ voltage, fs is the switching frequency, and Lm $>>$ Leq. Power will be transferred to the high-side voltage source through the flyback snubber, and the snubber will regulate clamping capacitor voltage $\mathrm{V}_{C}$ to $\mathrm{V}_{\mathrm{C}}(\mathrm{R})$ within one switching cycle $\mathrm{Ts}(=1 / \mathrm{fs})$. Note that the flyback snubber does not operate over the interval of inductance current $i_{p}$ increasing toward $i_{L}$. The processed 
power by the flyback snubber is typically around $5 \%$ of the full-load power for low-voltage applications. With the flyback snubber, the energy absorbed in $\mathrm{C}_{\mathrm{C}}$ will not flow through switches $\mathrm{M} 1-\mathrm{M} 4$, which can reduce their current stress dramatically. Theoretically, it can reduce the current stress from $2 \mathrm{i}_{\mathrm{L}}$ to $\mathrm{i}_{\mathrm{L}}$. For reducing conduction loss, the high-side switches $\mathrm{M}_{5}-\mathrm{M}_{8}$ are operated with synchronous switching. The operation waveforms of step-up conversion are shown in Fig 4. A detailed description of a half-switching cycle operation is shown as follows.

Mode $1\left[\mathrm{t}_{0} \leq \mathrm{t}<\mathrm{t}_{1}\right]$ :

In this mode, all of the four switches $\mathrm{M}_{1}-\mathrm{M}_{4}$ are turned $\mathrm{ON}$. Inductor $\mathrm{Lm}$ is charged by $\mathrm{V}_{\mathrm{LV}}$, inductor current $i_{L}$ increases linearly, and the primary winding of the transformer is short-circuited. The equivalent circuit is shown in Fig 3(a)

Mode $2\left[\mathrm{t}_{1} \leq \mathrm{t}<\mathrm{t}_{2}\right]$ :

At $t_{1}, M_{1}$ and $M_{4}$ remain conducting, while $\mathrm{M}_{2}$ and $\mathrm{M}_{3}$ are turned OFF. Clamping diode Dc conducts until the current difference $\left(i_{L}\left(t_{2}\right)-i p\left(t_{2}\right)\right)$ drops to zero at $t=t_{2}$. Moreover, the body diodes of switch pair $\left(M_{5}\right.$ , $\mathrm{M}_{8}$ ) are conducting to transfer power. During this interval, the current difference $\left(\mathrm{i}_{\mathrm{L}}(\mathrm{t})-\mathrm{ip}(\mathrm{t})\right)$ flows into clamping capacitor $\mathrm{C}_{\mathrm{C}}$. The equivalent circuit is shown in Fig $3(\mathrm{~b})$.

Mode $3\left[\mathrm{t}_{2} \leq \mathrm{t}<\mathrm{t}_{3}\right]$ :

At $t_{2}$, clamping diode Dc stops conducting, and the flyback snubber starts to operate. At this time, clamping capacitor $\mathrm{Cc}$ is discharging and flyback inductor is storing energy. Switches $\mathrm{M}_{1}$ and $\mathrm{M}_{4}$ still stay in the ON state, while $\mathrm{M}_{2}$ and $\mathrm{M}_{3}$ remain OFF. The body diodes of switch pair $\left(\mathrm{M}_{5}, \mathrm{M}_{8}\right)$ remain $\mathrm{ON}$ to transfer power. The equivalent circuit is shown in Fig 3(c).

Mode $4\left[\mathrm{t}_{3} \leq \mathrm{t}<\mathrm{t}_{4}\right]$ :

At $t_{3}$, the energy stored in flyback inductor is transferred to the high-voltage side. Over this interval, the flyback snubber will operate independently to regulate $V_{C}$ to $V_{C}(R)$. The switches $M_{1}$ and $M_{4}$ and diodes $D_{5}$ and $D_{8}$ are still conducting to transfer power from $V_{L V}$ to $V_{H V}$. The equivalent circuit is shown in Fig 3 (d).

Mode $5\left[t_{4} \leq t<t_{5}\right]$ :

At $t_{4}$, capacitor voltage $V_{C}$ has been regulated to $V_{C}(R)$, and the snubber is idle. Over this interval, the main power stage is still transferring power from $V_{\mathrm{LV}}$ to $\mathrm{V}_{\mathrm{HV}}$. It stops at $\mathrm{t}_{5}$ and completes a half-switching cycle operation. The equivalent circuit is shown in fig $3(\mathrm{e})$.
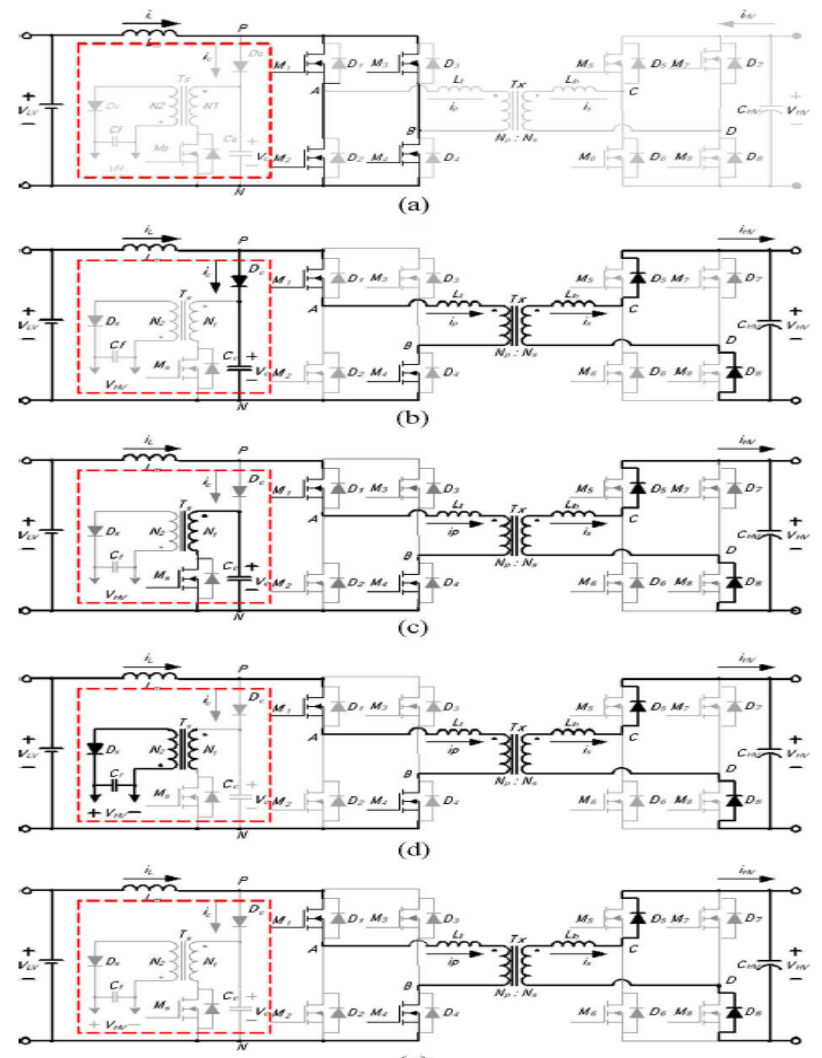

(e)

Figure 3. Operation Modes Of Step Up Conversion 


\section{Step-Down Conversion}

In this mode leakage inductance of the transformer at the low-voltage side is reflected to the highvoltage side. In the step-down conversion, switches $\mathrm{M}_{5}-\mathrm{M}_{8}$ are operated like a buck converter, in which switch pairs $\left(\mathrm{M}_{5}, \mathrm{M}_{8}\right)$ and $\left(\mathrm{M}_{6}, \mathrm{M}_{7}\right)$ are alternately turned $\mathrm{ON}$ to transfer power from $\mathrm{V}_{\mathrm{HV}}$ to $\mathrm{V}_{\mathrm{LV}}$. Switches M1-M4 are operated with synchronous switching to reduce conduction loss. For alleviating leakage inductance effect on voltage spike, switches $\mathrm{M}_{5}-\mathrm{M}_{8}$ are operated with phase-shift manner. There is no need to absorb the current difference between $\mathrm{i}_{\mathrm{L}}$ and ip .

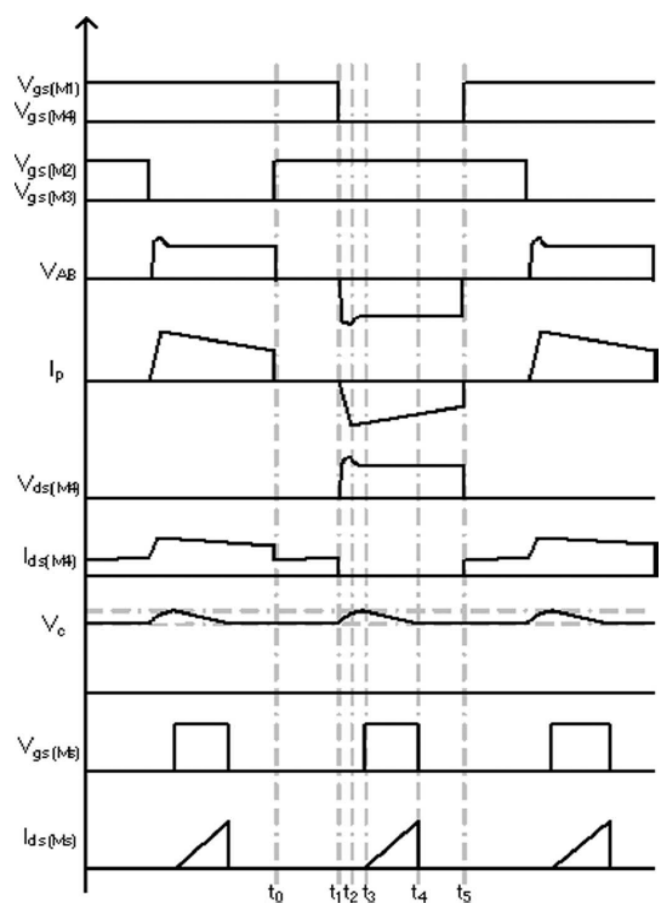

Figure 4. Operation Waveforms of Step Up Conversion

The operation waveforms of step-down conversion are shown in Figure 6. A detailed description of a half-switching cycle operation is shown as follows.

Mode $1\left[\mathrm{t}_{0} \leq \mathrm{t}<\mathrm{t}_{1}\right]$ :

In this mode, $\mathrm{M}_{5}$ and $\mathrm{M}_{8}$ are turned $\mathrm{ON}$, while $\mathrm{M}_{6}$ and $\mathrm{M}_{7}$ are in the OFF state. The high-side voltage $\mathrm{V}_{\mathrm{HV}}$ is immediately exerted on the transformer, and the whole voltage is exerted on the equivalent inductance Leq and causes the current to rise. With the transformer current increasing linearly toward the load current level at $\mathrm{t}_{1}$, the switch pair $\left(\mathrm{M}_{1}, \mathrm{M}_{4}\right)$ are conducting to transfer power, and the voltage across the transformer terminals on the current-fed side changes immediately to reflect the voltage from the voltage-fed side. The equivalent circuit is shown in Fig 5 (a).

Mode $2\left[\mathrm{t}_{1} \leq \mathrm{t}<\mathrm{t}_{2}\right]$ :

At $t_{1}, M_{8}$ remains conducting, while $M_{5}$ is turned OFF. The body diode of $M_{6}$ then starts to conduct the freewheeling leakage current. The transformer current reaches the load-current level at $t_{1}$, and $V_{A B}$ rises. Clamping diode Dc starts to conduct the resonant current of Leq and the clamp capacitor $\mathrm{C}_{\mathrm{C}}$. This process ends at $t_{2}$ when the resonance goes through a half resonant cycle and is blocked by the clamping diode $\mathrm{Dc}$. The equivalent circuit is shown in Fig 5 (b).

Mode $3\left[\mathrm{t}_{2} \leq \mathrm{t}<\mathrm{t}_{3}\right]$ :

At $t_{2}$, with the body diode of switch $\mathrm{M}_{6}$ conducting, $\mathrm{M}_{6}$ can be turned $\mathrm{ON}$ with zero-voltage switching (ZVS). The equivalent circuit is shown in Fig 5 (c).

Mode $4\left[\mathrm{t}_{3} \leq \mathrm{t}<\mathrm{t}_{4}\right]$ :

At $t_{3}, M_{6}$ remains conducting, while $M_{8}$ is turned OFF. The body diode of $M_{7}$ then starts to conduct the freewheeling leakage current. The equivalent circuit is shown in Fig 5 (d).

Mode $5\left[\mathrm{t}_{4} \leq \mathrm{t}<\mathrm{t}_{5}\right]$ :

At $t_{4}$, with the body diode of switch $\mathrm{M}_{7}$ conducting, $\mathrm{M}_{7}$ can be turned ON with ZVS. Over this interval, the active switches change to the other pair of diagonal switches, and the voltage on the transformer 
reverses its polarity to balance flux. It stops at $t_{5}$ and completes a half-switching cycle operation. The equivalent circuit is shown in Fig 5 (e).
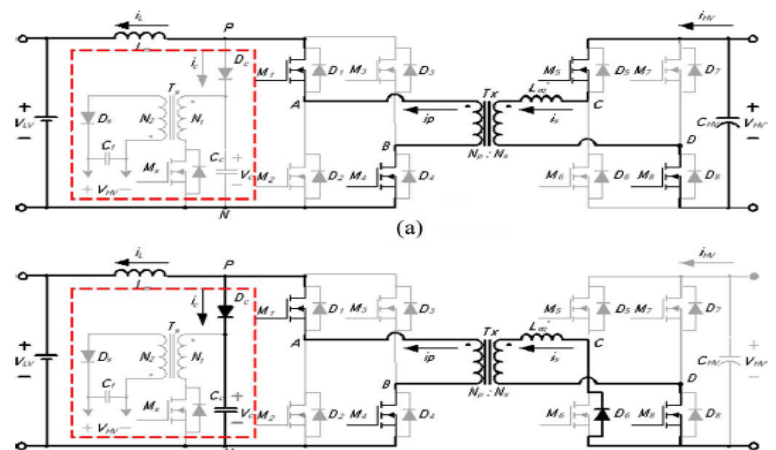

(b)

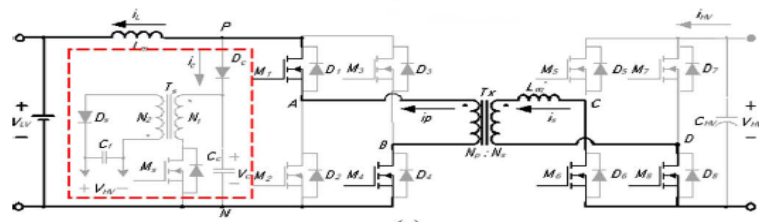

(c)

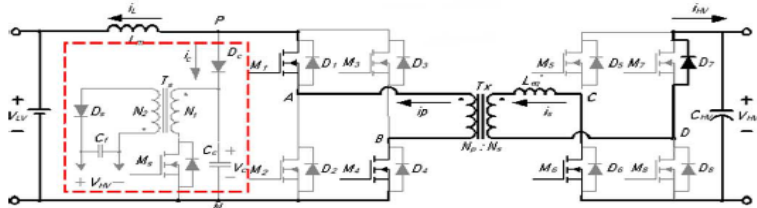

(d)

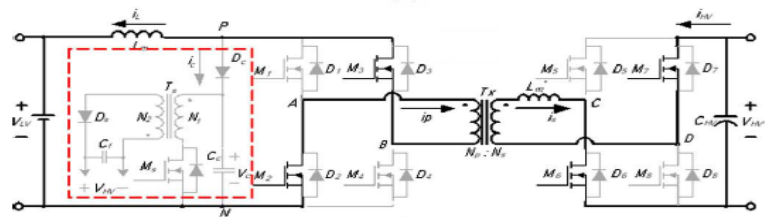

(e)

Figure 5. Operation Modes Of Step Down Conversion

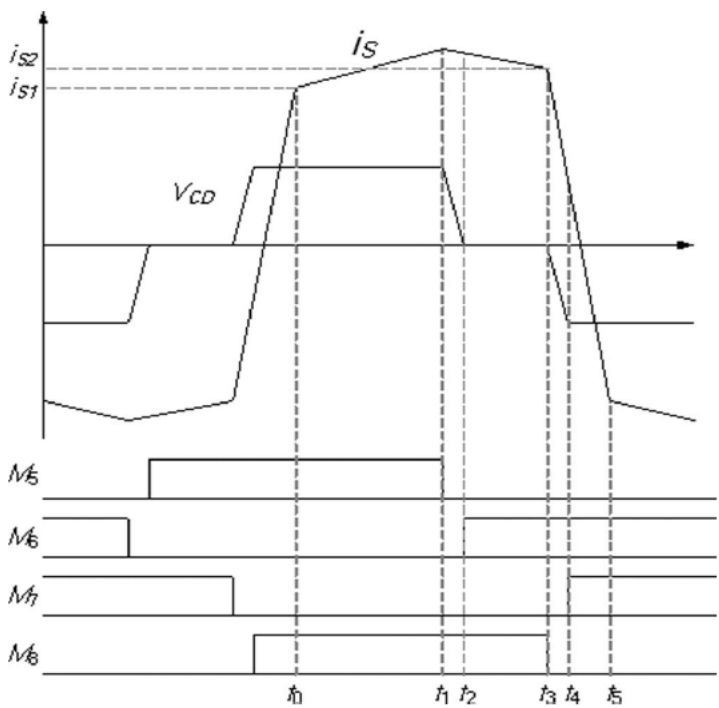

Figure 6. Operation Waveforms Of Step Down Conversion 


\subsection{Low-Voltage Side}

\section{Practical Consideration}

Switch pairs $\left(\mathrm{M}_{1}, \mathrm{M}_{4}\right)$ and $\left(\mathrm{M}_{2}, \mathrm{M}_{3}\right)$ are turned $\mathrm{ON}$ alternately under any load condition. Its minimum conduction time is

$$
\begin{aligned}
& \mathrm{T}_{\mathrm{C}(\text { min })}=\frac{\mathrm{L}_{\mathrm{eq}} \mathrm{i}_{\mathrm{L}}}{\mathrm{V}_{\mathrm{AB}}} \\
& \mathrm{L}_{\mathrm{eq}}=\mathrm{L}_{11}+\mathrm{L}_{\mathrm{lh}} \times\left(\frac{\mathrm{N}_{\mathrm{p}}}{\mathrm{N}_{\mathrm{s}}}\right)^{2}
\end{aligned}
$$

$\mathrm{L}_{11}$ - Leakage inductance of low voltage side

$\mathrm{L}_{\mathrm{lh}}$ - Leakage inductance of high voltage side

$\frac{N_{p}}{N_{s}}$ - Turns ratio

\subsection{Clamping Capacitor}

For absorbing the energy stored in the leakage inductance and to limit the capacitor voltage to a specified minimal value $\mathrm{V}_{\mathrm{c} l}$, capacitance $\mathrm{Cc}$ has to satisfy the following inequality

$$
\mathrm{C}_{\mathrm{C}} \geq \frac{\mathrm{L}_{\mathrm{eq}}\left(\mathrm{i}_{\mathrm{L}}-\mathrm{i}_{\mathrm{p}}\right)^{2}}{\mathrm{~V}_{\mathrm{c} l}{ }^{2}}
$$

\section{Simulation}

An isolated bidirectional dc-dc converter with a $\mathrm{R}$ load is selected. Its model is simulated with and without a flyback snubber. Simulation model and results of isolated bidirectional dc-de converter with and without flyback snubber in boost mode is shown in figures 7 to 12 . The input dc voltage given is $48 \mathrm{~V}$ and the output dc voltage obtained is $280 \mathrm{~V}$. Simulation models for without and with flyback snubber is shown in figures 7 and 8 respectively. In an isolated bidirectional $\mathrm{dc}-\mathrm{dc}$ converter without flyback snubber, the voltage spikes are of large values. By comparing the results it can be see that $78 \%$ to $80 \%$ voltage spikes can be reduced with a flyback snubber. Simulation parameters are as shown in the Table 1.

Table 1

\begin{tabular}{|l|l|}
\hline Parameter & Value \\
\hline Current fed inductor, $\mathrm{L}_{\mathrm{m}}$ & $500 \mu \mathrm{H}$ \\
\hline Clamping capacitor, $\mathrm{C}_{\mathrm{c}}$ & $1 \mu \mathrm{F}$ \\
\hline Resistor, $\mathrm{R}$ & $100 \Omega$ \\
\hline Switching frequency, $\mathrm{f}_{\mathrm{s}}$ & $25 \mathrm{kHz}$ \\
\hline
\end{tabular}

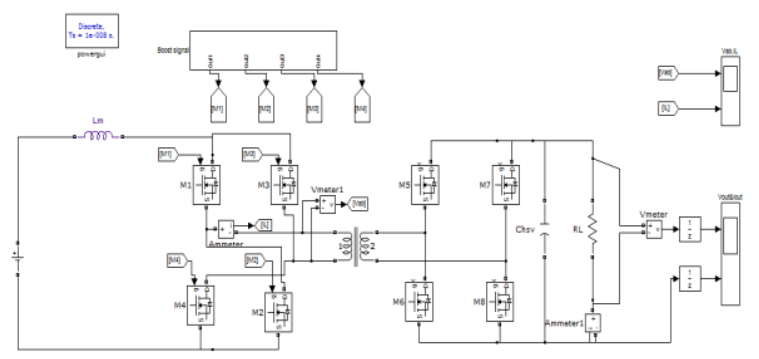

Figure 7. Simulation Model For Boost Operation Without flyback Snubber 


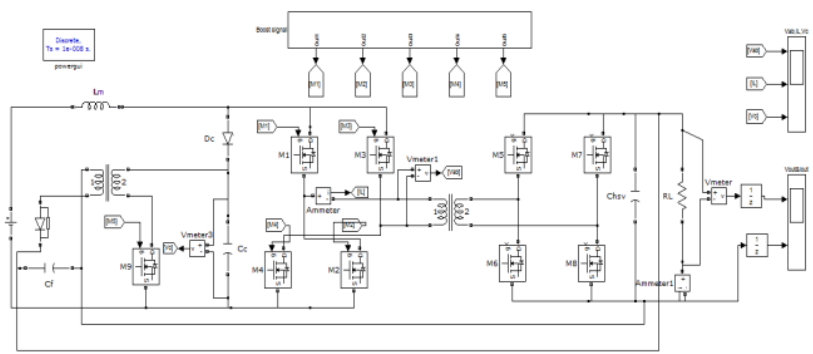

Figure 8. Simulation Model For Boost Operation With a flyback Snubber

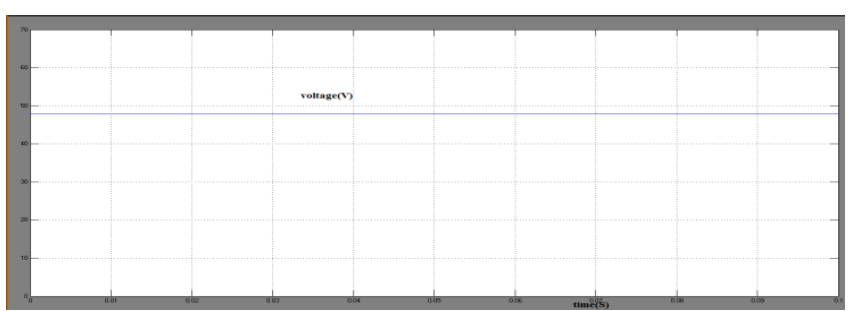

Figure 9. Input Voltage

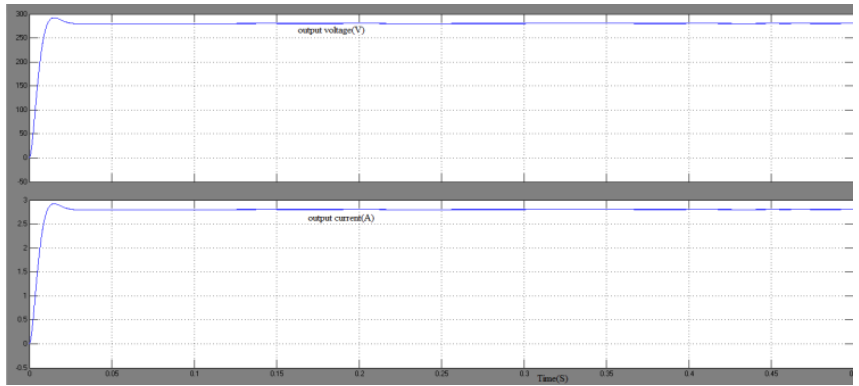

Figure 10. Output Voltage And Current $\mathrm{V}_{\mathrm{s}}$ Time

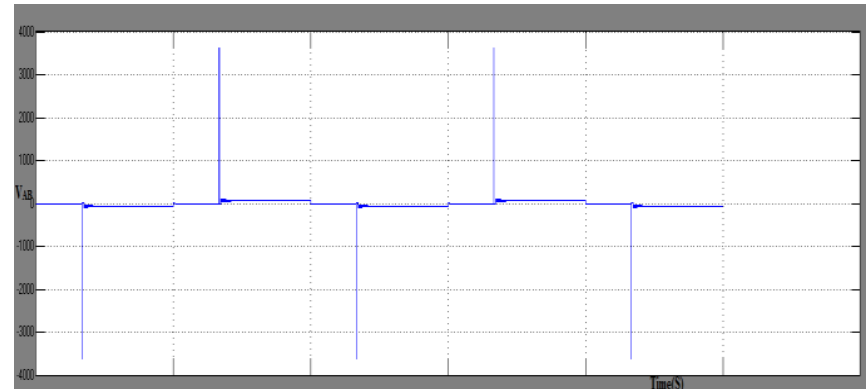

Figure $11 . \mathrm{V}_{\mathrm{AB}}$ (voltage across the primary) for without flyback snubber)

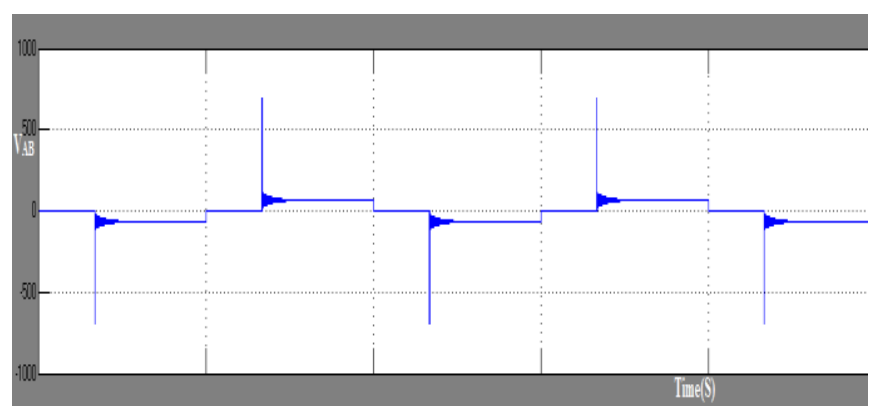

Figure $12 . \mathrm{V}_{\mathrm{AB}}$ (voltage across the primary) for with flyback snubber) 


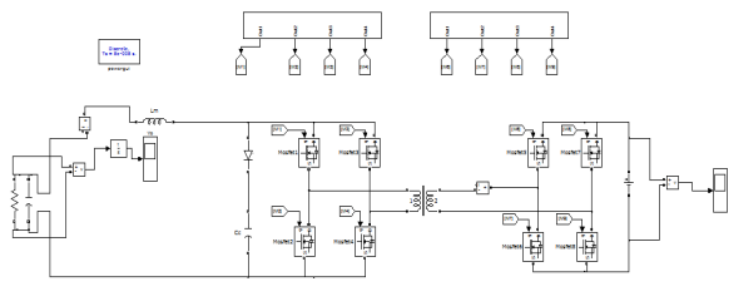

Figure 13. Simulation Model For Buck Operation

Simulation model for buck operation with $\mathrm{R}$ load is also shown in figure13. The effect of flyback snubber is only in boost mode operation. In buck mode it is inactive. The input voltage given is $360 \mathrm{~V}$ and the output obtained is $50 \mathrm{~V}$.

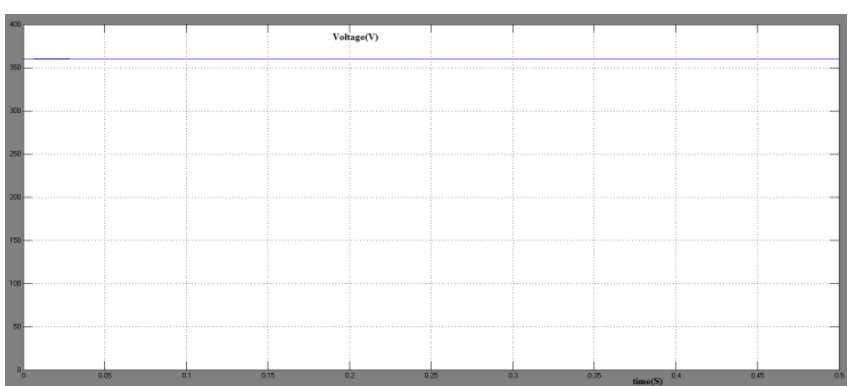

Figure 14. Input Voltage

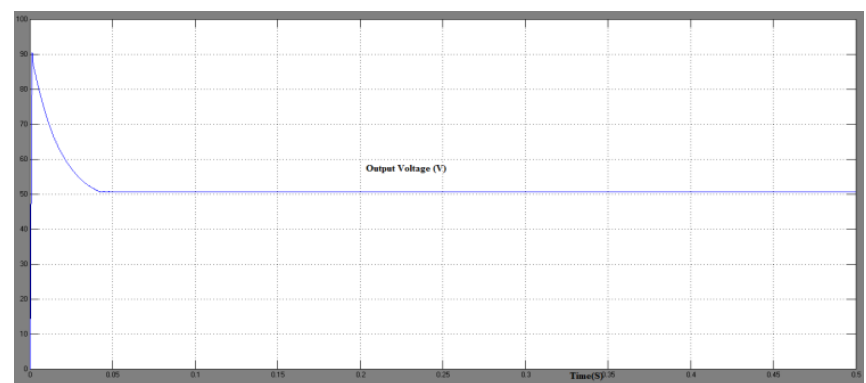

Figure 15. Output Voltage

VII. Hardware Implementation

Hardware circuit of isolated bidirectional dc - dc converter with flyback snubber in boost mode is implemented and got the boosted dc output and observed the other waveforms. Experimental set up of the hardware of the isolated bidirectional dc-dc converter is shown in fig 16.

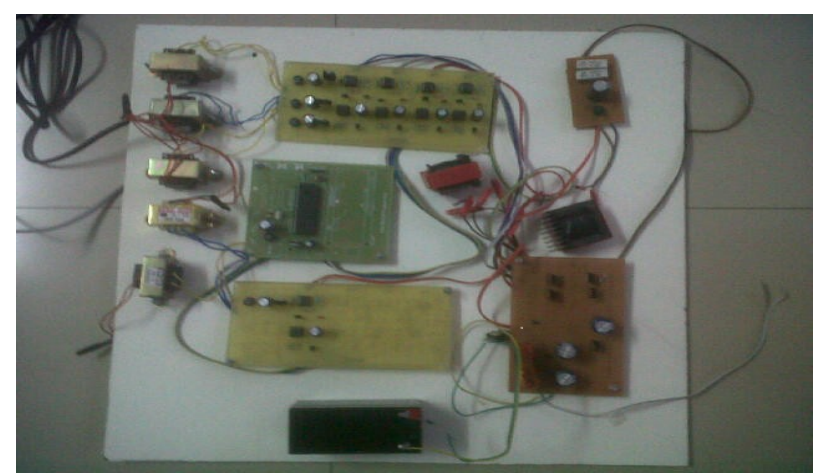

Figure 16. Hardware Setup 


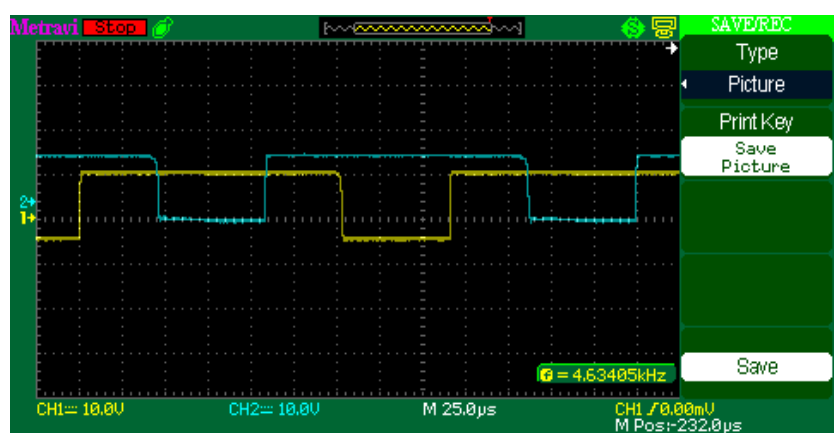

Figure 17. Pulses For MOSFETS $\mathrm{M}_{1} \mathrm{M}_{4}$ AND $\mathrm{M}_{2} \mathrm{M}_{3}$.

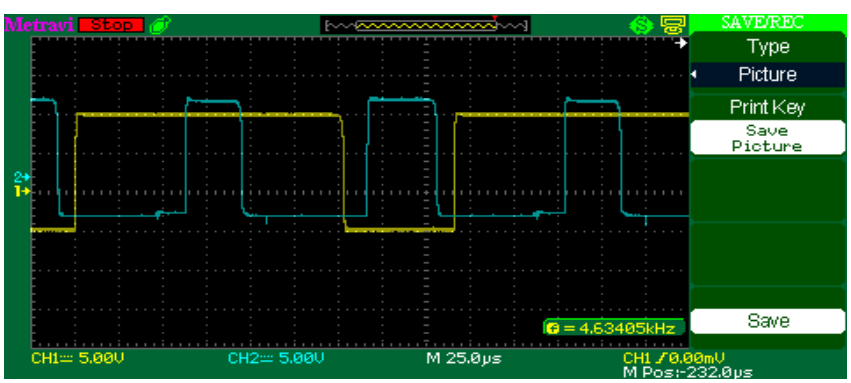

Figure 18. Pulses For MOSFETS $\mathrm{M}_{1} \mathrm{M}_{4}$ and $\mathrm{M}_{9}$

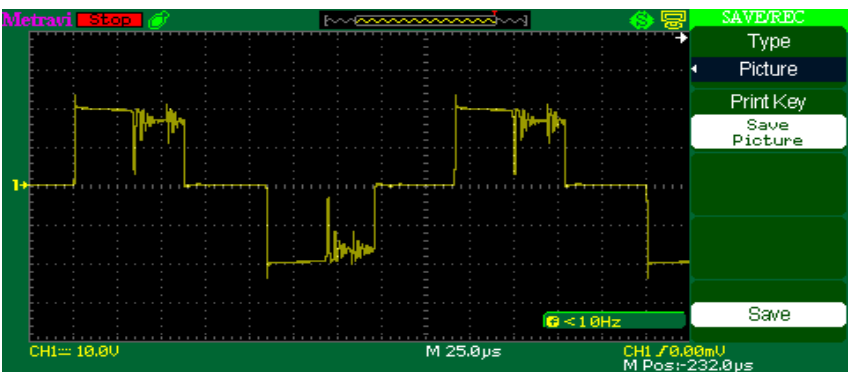

Figure 19. Waveform Of $\mathrm{V}_{\mathrm{AB}}$

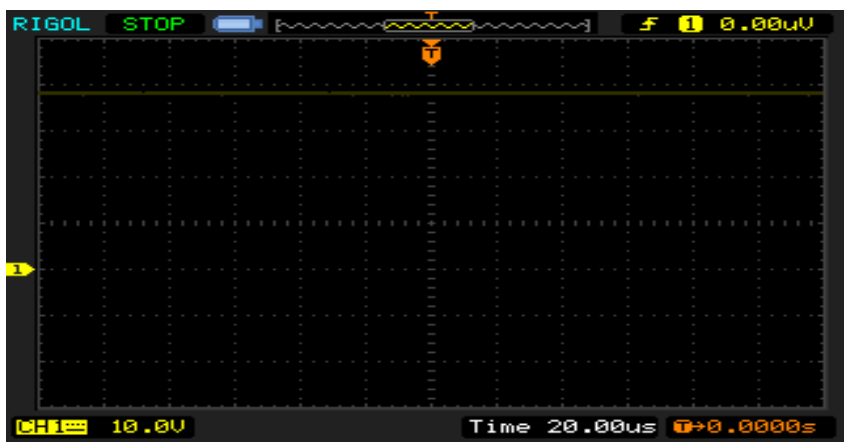

Figure 20. Output Voltage

The waveforms obtained from the hardware follow the shape of the simulation results. The waveforms are shown in figures 17 to 20 . The input given is $10 \mathrm{~V}$ from a battery. The input is boosted and the output is $39 \mathrm{~V}$.

\section{Conclusion}

In this work an isolated bidirectional de - dc converter is simulated using MATLAB SIMULINK tool . The simulation model includes converter with and without the flyback snubber. Then the simulation results of both of them are compared. From comparison of simulation results it can be observed that the voltage spikes can be reduced to a great extent by using flyback snubber. About $78 \%$ to $80 \%$ voltage spikes can be reduced. The hardware of the isolated bidirectional dc-dc converter with flyback snubber in boost mode is implemented and experimental waveforms follow the shape of the simulation results. But the hardware results still contains 
spikes. From the simulation results and hardware results, it can be concluded that the spikes will be larger in the hardware results if there is no flyback snubber.

\section{References}

[1.] Tsai-Fu Wu, Senior Member, IEEE, Yung-Chu Chen, Jeng-Gung Yang, and Chia-Ling Kuo, "Isolated Bidirectional FullBridge DC-DC Converter With a Flyback Snubber, IEEE Transactions On Power Electronics", Vol. 25, No. 7, July 2010

[2.] K.Wang, C. Y. Lin, L. Zhu, D. Qu, F. C. Lee, and J. S. Lai, "Bi-directional DC to DC converters for fuel cell systems," in Proc. Power Electron. Transp., 1998, pp. 47-51.

[3.] S.Yujin and P.N. Enjeti, "A newsoft switching technique for bi-directional power flow, full- bridge DC-DC converter," in Proc. Ind. Appl.Conf., 2002, vol. 4, pp. 2314-2319.

[4.] O. Garcia, L. A. Flores, J. A. Oliver, J. A. Cobos, and J. De la pena, "Bi-directional DC-DC converter for hybrid vehicles," in Proc.Power Electron. Spec. Conf., 2005

[5.] C. Qiao and K. M. Smedley, "An isolated full bridge boost converter with active soft switching," in Proc. Power Electron. Spec. Conf., 2001, pp. 896-903.

[6.] R. Watson and F. C. Lee, "A soft-switched, full-bridge boost converter employing an active- clamp circuit," in Proc. Power Electron. Spec. Conf., 1996

[7.] K. Wang, F. C. Lee, and J. Lai, "Operation principles of bi-directional full-bridge DC/DC converter with unified soft-switching

[8.] scheme and softstarting capability," in Proc. Appl.Power Electron. Conf., 2000, pp. 111-118.

[9.] F. Krismer and J. W. Kolar, "Accurate small-signal model for the digital control of an automotive bidirectional dual active bridge," [10.] IEEE Trans. Power Electron., vol. 24, no.12, pp. 2756-2768, Dec. 2009.

[11.] T. Reimann, S. Szeponik, and G. Berger, "A novel control principle of bi-directional DC-DC power conversion," in Proc. Power

[12.] Electron. Spec. Conf., 1997, vol. 2, pp. 978-984. 